\title{
Implant-related Metal Hypersensitivity-A Cause for Concern: A Report of Two Cases and Literature Review
}

\author{
${ }^{1}$ Rajendra Kanojia, ${ }^{2}$ Vishal Kumar, ${ }^{3}$ Bhavuk Garg, ${ }^{4}$ Mandeep S Dhillon
}

\begin{abstract}
The evolution of orthopedic implants has witnessed a great evolution and allowed insights into the various metals and alloys compatible with the human body. However, some recent reports have raised concerns regarding hypersensitivity to several metals used in orthopedic implants. These cases are mostly documented in the field of arthroplasty.

Metal ion release following hip or knee arthroplasty is a known phenomenon and associated immune reactions to these metal ions have been implicated in the causation of these hypersensitivity reactions. These reactions frequently lead to poor outcome following these implant surgeries. We here present two rare cases of metal induced hypersensitivity reactions following orthopedic surgeries. We have also reviewed the literature in this context to look into the various causes of metal reactions, types of implant involved in hypersensitivity, methods of testing and management options in these cases.
\end{abstract}

Keywords: Metal sensitivity, Metal allergy, Hypersensitivity reaction.

How to cite this article: Kanojia R, Kumar V, Garg B, Dhillon MS. Implant-related Metal Hypersensitivity-A Cause for Concern: A Report of Two Cases and Literature Review. J Postgrad Med Edu Res 2014;48(1):37-39.

Source of support: Nil

Conflict of interest: None

\section{INTRODUCTION}

Metal sensitivity caused by immune reaction toward metal ions released either by corrosion is well documented but its incidence has decreased in modern times due to improved understanding and standardized metallurgical techniques used for manufacturing alloys. This concern has raised again due to increasing use of large diameter metal on metal articulations. These large metal on metal articulations lead to greater concentration of metal ions in blood, endangering the patient towards risk of several adverse effects. The risk of metal sensitivity with routine orthopedic implants is not the same as with joint prosthesis. Here, we present two

${ }^{1}$ Associate Professor, ${ }^{2,3}$ Assistant Professor, ${ }^{4}$ Professor

${ }^{1,2,4}$ Department of Orthopedics, Postgraduate Institute of Medical Education and Research, Chandigarh, India

${ }^{3}$ Department of Orthopedics, All India Institute of Medical Sciences, New Delhi, India

Corresponding Author: Rajendra Kanojia, Associate Professor, Department of Orthopedics, Postgraduate Institute of Medical Education and Research, Chandigarh, India Phone: 09914209750, e-mail: drrajendra_kanojia@yahoo.co.in such rare cases of hypersensitivity associated with nonarthroplasty implants.

\section{CASE REPORTS}

\section{Case 1}

A 70 years old lady with fracture of left intertrochanteric femur presented to our institute in August 1989. Open reduction and internal fixation with Richards hip compression screw and side plate along with an additional transfixation screw at the greater trochanter was done (Fig. 1). Fracture united after 4 months and patient gradually regained ambulatory status. However, after 6 months, she developed itching all over the body, swelling in the left lower limb and patchy discoloration of the toes, which gradually progressed proximally. The symptoms of itching, swelling and discoloration continued to increase till the implant was removed in 1993. After removal of implant, patient became completely symptom free in 2 months.

\section{Case 2}

The second patient presented with nonunion of fracture both bones of leg, who was treated with application of ring fixator (Fig. 2). After 1 month, this patient presented with itchy eruptions all over the body. These eruptions were centered near the wires of ring fixator. The fracture united in 4 months however his itching and eruptions continued to worsen. Finally, his implant was removed after a total of 7 months and he was relieved of his symptoms 3 weeks after removal of his ring fixator.
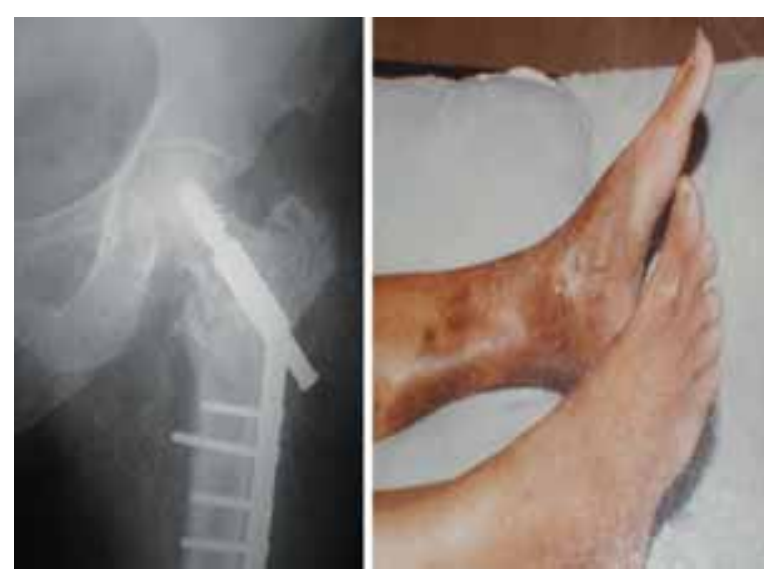

Fig. 1: Operated intertrochanteric fracture showing loosening of implant metal reaction - patientleg and ankle with changes in skin color 


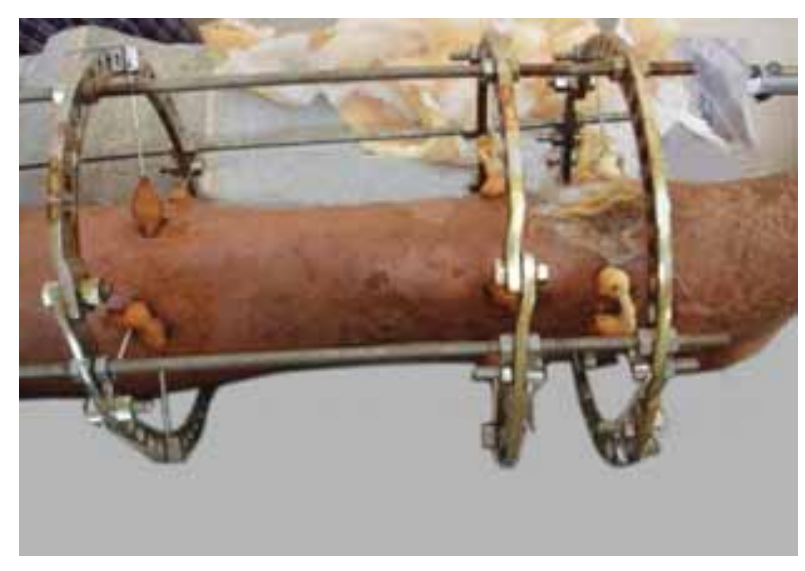

Fig. 2: Operated nonunion of leg treated with llizarov ring developed skin blackening

\section{DISCUSSION}

Laugier and Foussereau ${ }^{1}$ in 1964 first described the dermatitis caused by reaction to an orthopedic implant. Nickel was released from stainless steel implant by process of the action of perspiration in blood or physiological saline solution. Samitz and Katz ${ }^{2}$ found that metal ions, released by embedded implant(s) in animals, were found in the lungs (nickel), the spleen (nickel and cobalt) and the kidneys (nickel, cobalt and molybdenum). The concentration of metallic ions in the tissues decreased as the time passed in most sites except the spleen.

There are several evidences of metal corrosion demonstrated in humans. During revision hip joint replacements, Langlais et $\mathrm{al}^{3}$ found black particles of nickel and cobalt in the tissue around the prosthesis. High concentration of the nickel was found in $2 \%$ of the cases in the tissues in revision hip arthroplasties. ${ }^{4}$ High level of cobalt and chromium in plasma and urine were reported in nine asymptomatic patients who had been operated and put on metal on metal hip prosthesis. ${ }^{5}$

In a study of 50 patients of total joint replacement, sensitivity for cobalt, chromium, nickel, molybdenum, vanadium and titanium were tested. In that 19 patients (38\%) were positive to one or two metals and there were no evidences of prior metal allergy or exposure in these patients. ${ }^{5}$

\section{IMPORTANCE OF SKIN PATCH TESTING}

There is enough evidence of positive skin patch test to nickel, chromium and cobalt in asymptomatic patients having an orthopedic implant in situ. In patients with hip-prosthesis, the number of positive skin patch test ranged from $10 \%$ to as many as $56 \%{ }^{6}$ Similarly results of prospective studies of patients who had a metal on plastic prosthesis have shown 2.6 to $6 \%$ of positive skin patch test, while retrospective studies found it to be 2.2 to $4 \%{ }^{7}$

\section{PATTERN OF PRESENTATION}

The most common presentation is of eczematous dermatitis (localized or diffuse) ${ }^{8}$ It may begin in the skin over the implant and later become generalized. In another report of three patients of dermal and hypodermal inflammatory reaction on the skin over the hardware, two had cellulitis (complicated by sterile abscess in one) secondary to co-sensitization to chromium and cobalt. ${ }^{9-11}$ Generalized urticaria and myositis has also been reported. ${ }^{12,13}$

The basic pathophysiology of this can be divided into stage of corrosion, followed by second stage of localization of the products of these internal wear. Although some are excreted through the perspiration and in the urine excretion, in stage three, some of these intermediary metal ions behave as hapten and link to dermal proteins, which later on leads to immune reaction. Next stage is of an immediate type III hypersensitivity reaction leading to urticaria secondary to immune complex deposit due to the liberation of lymphokines. In the last stage, liberation of lysosomal enzymes and degranulation of dermal mast cells occurs presenting as a dermatoepidermal inflammatory reaction and skin changes. ${ }^{9}$

\section{DIAGNOSTIC CRITERIA}

Several authors have proposed diagnostic criteria for orthopedic dermatitis. ${ }^{13,14}$ One such criterion suggests two stage approach in which, first stage consists of a positive diagnosis of orthopedic dermatitis and second stage is the diagnosis of pathophysiological mechanisms.

\section{CONCLUSION}

We propose that cases of hypersensitivity due to orthopedic implants are either undiagnosed or misdiagnosed. Hence, the current report attempts to increase awareness levels in nonarthroplasty implant hypersensitivity, and may help in early diagnosis and treatment of such reactions. Some prospective studies as well as basic research needs to be conducted to define the role of hypersensitivity reactions in patients with implant.

\section{REFERENCES}

1. Laugier P, Froussereau JP. Les dermites allergiques a distance provoquces par le materiel d osteosynthese. Gaz Med France 1966;73:3409-3418.

2. Samitz MH, Katz SA. Nickel dermatitis hazards from prosthesis in vivo and in vitro solubilization studies. British J Dermatology 1976;92:287-290.

3. Langlas F, Postel M, Berry JP, Charpentier LY. Lintolerance aux debris d usure des prosthesis. Bioimmunologique anatomopathologique de 30 cas. Internat Ortho 1980;4:145-153. 
4. Mears DC. Electron -probe microanalysis of tissue and cells from implant areas. J Bone and Joint Surg 1966;48-b:567-576.

5. Coleman RF, Herrigton J, Sccales TJ. Concentration of wear products in hair, blood and urine after total hip replacement. British Med J 1973;1:527-529.

6. Nater JP, Brian RG, Deutman R, Mulder TJ. The development of metal hypersensitivity in patients with metal to plastic hip arthroplasties. Contact Dermat 1976;2:259-261.

7. Stella M, Montaldi A, Rossi RG, Andlevis AG. Clastogenic effects of chromium on human lymphocytes in vitro and vivo. Mutat Res 1982;101:151-164.

8. Symeonies PP, Paschaloglou C, Andpapageorgiou S. An allergic reaction after internal fixation of a fracture using a plate. J. Allergy and Clin Immunol 1973;51:251-252.
9. Soborg M, Bendixen G. Human lymphocytic migration as a parameter of hypersensitivity. Acta Med Scan 1967:p. 181.

10. Benveniste J, et al. Detection of immediate hypersensitivity in rabbits by direct basophil degranulation. J Allergy and Clin Immunol 1977;59:271-279.

11. Donati ME, et al. The effects of metal corrosion debries on immune system cells. Chir Organi Mov 1998;8:387-393.

12. Hallab N, Jacob J, Black J. Hypersensitivity to metallic biomaterials; a review of leukocyte migration inhibition assays. Biomaterials 2000;21:1301-1314.

13. Retchel MM, Favour CB. The influence of a plasma factor on in vitro leucocytes migration. Science 1953;118:79-80.

14. Merie C. Generlized eczema from vittalium osteo-synthesis material. Contact Dematitis 1992;27:257-258. 